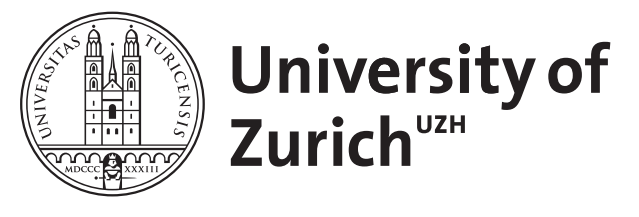

\title{
Health effects on children's willingness to compete
}

Bartling, Björn ; Fehr, Ernst ; Schunk, Daniel

\begin{abstract}
The formation of human capital is important for a society's welfare and economic success. Recent literature shows that child health can provide an important explanation for disparities in children's human capital development across different socio-economic groups. While this literature focuses on cognitive skills as determinants of human capital, it neglects non-cognitive skills. We analyze data from economic experiments with preschoolers and their mothers to investigate whether child health can explain developmental gaps in children's non-cognitive skills. Our measure for children's noncognitive skills is their willingness to compete with others. Our findings suggest that health problems are negatively related to children's willingness to compete and that the effect of health on competitiveness differs with socioeconomic background. Health has a strongly negative effect in our sub-sample with low socioeconomic background, whereas there is no effect in our sub-sample with high socio-economic background.
\end{abstract}

DOI: https://doi.org/10.1007/s10683-011-9288-2

Posted at the Zurich Open Repository and Archive, University of Zurich

ZORA URL: https://doi.org/10.5167/uzh-51439

Journal Article

Originally published at:

Bartling, Björn; Fehr, Ernst; Schunk, Daniel (2012). Health effects on children's willingness to compete. Experimental Economics, 15(1):58-70.

DOI: https://doi.org/10.1007/s10683-011-9288-2 


\title{
Health Effects on Children's Willingness to Compete
}

\author{
Björn Bartling, Ernst Fehr, and Daniel Schunk ${ }^{1}$
}

May 15, 2011

forthcoming in: Experimental Economics

\begin{abstract}
The formation of human capital is important for a society's welfare and economic success. Recent literature shows that child health can provide an important explanation for disparities in children's human capital development across different socio-economic groups. While this literature focuses on cognitive skills as determinants of human capital, it neglects non-cognitive skills. We analyze data from economic experiments with preschoolers and their mothers to investigate whether child health can explain developmental gaps in children's non-cognitive skills. Our measure for children's noncognitive skills is their willingness to compete with others. Our findings suggest that health problems are negatively related to children's willingness to compete and that the effect of health on competitiveness differs with socio-economic background. Health has a strongly negative effect in our sub-sample with low socioeconomic background, whereas there is no effect in our sub-sample with high socio-economic background.
\end{abstract}

JEL-code: C90, I10, J24

Keywords: willingness to compete, non-cognitive skills, human capital, health, household survey studies

\footnotetext{
${ }^{1}$ Bartling and Fehr: University of Zurich, Department of Economics, Blümlisalpstrasse 10, 8006 Zurich, Switzerland. Schunk: University of Zurich and University of Mainz, Department of Economics, Saarstraße 21, 55099 Mainz, Germany. We would like to thank Jürgen Schupp, Katharina Spieß, and Gert Wagner from the German Institute for Economic Research in Berlin (DIW) and the Free University Berlin for their very generous support of this project. We also thank Sally Gschwend, Michel Maréchal, and Sonja Vogt for detailed comments, as well as Agnes Jänsch and Andreas Stocker from TNS Infratest for the implementation of the experiments and organization of the interviews.
} 


\section{Introduction}

What are the determinants of human capital formation in children, and are these determinants related to parental socio-economic background? These questions have been of enduring interest in virtually all branches of the social sciences (e.g., Heckman, 2007; Cunha and Heckman, 2009; Knudsen et al., 2006) because the formation of human capital is of fundamental importance for a society's welfare. In this paper, we use economic games and experimental tools in combination with household survey data to provide new insights in answering these questions.

From an economic perspective, the analysis of the association between parents' socioeconomic status and child developmental outcomes provides particularly important insights. Several studies showed that measures of developmental outcomes, e.g., children's cognitive scores, are significant determinants of adult human capital indicators, such as employment and earnings history (e.g., Dustmann et al., 2003) or participation in criminal and other risky activities (e.g., Cunha and Heckman, 2007; Heckman et al., 2006). Two important findings emerge from these studies: First, child health can offer an important explanation for disparities in children's cognitive development among different socio-economic groups (e.g., Case et al. 2005). Second, human capital is developed through an interactive process that requires not only cognitive skills, like mathematical abilities, but non-cognitive skills as well, such as social and emotional capacities (e.g., Dohmen et al., 2009, Heckman, 2007; Shonkoff and Phillips, 2000).

Surprisingly, however, despite regular emphasis on the importance of non-cognitive skills, previous studies did not investigate the extent to which child health is also an explanation for children's non-cognitive development, and how the development of these skills varies among different socio-economic groups. Our study aims to be a first step in this direction. It focuses on 
one important dimension of children's non-cognitive skills, namely their willingness to compete. ${ }^{2}$ An individual's willingness to compete with others is a crucial element of his fitness and success, not only from an evolutionary point of view but also from an economic perspective: work and career efforts are often driven by vigorous competition for promotion to better paid jobs associated with a high prestige. Less competitive people, however, shy away from direct competition for career opportunities. The willingness to compete is thus an important noncognitive determinant of human capital indicators, such as adult economic achievements and productivity (e.g., Niederle and Vesterlund, 2007; see also the extensive literature in evolutionary and social biology on the development of competitiveness, e.g., Knight, 2002). To the best of our knowledge, this is the only study to date using economic games and experimental tools in combination with household survey data to address the question whether child health can explain developmental gaps in non-cognitive skills.

An advantage of our approach is that incentivized experiments provide a precise measure of a child's willingness to compete. Specifically, we analyze a unique data set from several economic experiments implemented within a household survey study - the German SocioEconomic Panel (GSOEP) - with preschool children and their mothers. We measure children's desire to compete with others, henceforth denoted competitiveness, by giving them either the choice of competing in a tournament or receiving a piece rate in a task that requires skill, concentration, and effort. Since a tournament is intrinsically riskier than a piece rate, we also elicit the children's risk attitudes with incentivized experimental procedures. Our measure for children's health conditions is based on the information whether a child had a medical condition that forced him or her to see a medical practitioner at least once during the last three months before the experiments took place.

\footnotetext{
${ }^{2}$ Other important non-cognitive skills are, for example, patience, self control, perseverance, motivation, and selfesteem (Cunha and Heckman, 2009).
} 
Another advantage of our approach is that our experiments are integrated into a household survey. Thus, we have a very rich set of additional information about the children, including cognitive skills and personality traits, as well as data on the family's socio-economic background. We also used incentivized procedures to elicit the mothers' risk attitudes and use this information as a control variable in our analysis, because the decision to have the child visit a doctor could be related to the extent to which the mother is inclined to prevent risks.

We would like to note, however, that we use a contemporaneous measure of childhood health and not a measure of general health status during childhood. Similarly, since we do not have panel data, we have only a contemporaneous measure of competitiveness. Hence, our data do not allow us to follow the development of competitiveness and health in children. But we can test for a contemporaneous correlation between our measures while controlling for a number of potentially relevant factors.

Related Literature: Previous studies analyzed the relationship between socio-economic characteristics and child health. For example, a robust positive association between parents' socio-economic status and child health has been found in several countries such as the United States (Case et al., 2002), Canada (Currie and Stabile, 2003), and the United Kingdom (Currie et al., 2007). Several studies also analyzed the relationship between parents' socio-economic status and children's cognitive development and report that family economic resources are an important determinant of child cognitive outcomes (Aughinbaugh and Gittleman, 2003; Taylor et al. 2004; Blau, 1999). Complementary to this literature, scholars have studied the relation between health and cognitive skills (Paxson and Schady, 2007; Currie et al., 2010), with a particular interest in the question of whether this relationship differs by socio-economic characteristics (for a survey see Currie, 2009). Using British data, Case et al. (2005) find that children born into poorer families experience poorer childhood health and - controlling for parental income, education, and 
social class - that poorer childhood health is associated with significantly lower socio-economic status in adult life. Salm and Schunk (2011) use administrative data from Germany to show that mental health conditions are negatively related to children's cognitive skills and that health also accounts for developmental gaps between children of high and low socio-economic status. ${ }^{3}$

Our study contributes to the existing literature in two ways. First, we find that our measure of health condition is negatively associated with children's competitiveness. This suggests that child health is associated with human capital formation not only via cognitive, but also via non-cognitive skills. Second, we show that the association of our measure of health condition with our measure for non-cognitive skills differs, depending on the children's socioeconomic backgrounds. While health and competiveness are negatively associated for children with a low socio-economic background, we do not find an association for children with a high socio-economic background. This result mirrors previous findings that child health and cognitive skills are more negatively associated with a lower socio-economic background.

\section{Experimental Design}

This paper is based on a data set from a pilot study that explores the feasibility of integrating incentivized economic experiments into the German Socio-Economic Panel (GSOEP), a representative longitudinal survey of private households in Germany. ${ }^{4}$ The study targeted mothers with preschool children. In addition to answering a questionnaire, mothers also participated in choice experiments that took place in their households. We also conducted experiments with their children at their daycare centers. The experiments were adapted to take the time, technical, and spatial constraints into account, which arise when moving from the standard laboratory to the field (the mothers' households and children's daycare centers). Our sample

\footnotetext{
${ }^{3}$ There is also an emerging literature that uses economic experiments to measure skills, preferences, and behavioral patterns in children (e.g., Bettinger and Slonim, 2007; Sutter and Rützler, 2010).

${ }^{4}$ See http://www.diw.de/english/soep/29012.html
} 
consists of two sub-samples. The interviews and experiments for one sub-sample were conducted between May and November 2008 in the metropolitan area of Munich (Germany) and the interviews and experiments for the other sub-sample were conducted between July and October 2009 in Berlin (Germany). The interviews and experiments with the mothers were conducted by specially trained and experienced interviewers from the same professional survey company that also collects the data for the GSOEP. Two trained child psychologists performed the experiments with the children.

The sampling procedure was as follows. First, request letters were sent to a stratified random sample of daycare centers in the metropolitan area of Munich and Berlin. If a center participated, information leaflets and consent forms were forwarded to all mothers of 5 to 6 year old children at the center. In total, 118 mother and child pairs participated in the Munich subsample, and 214 participated in the Berlin sub-sample. The mothers went through a computer assisted personal interview in their households. In the first part, each mother filled out a survey about her personality, cognitive abilities, and socio-economic status. She also answered questions about the personality traits, cognitive skills, and health conditions of the child that took part in the experiments at the daycare centers. In the second part, we conducted a computerized experiment with the mothers to elicit their risk preferences. The measure of mothers' risk preferences serves as a control variable in our regression analyses of children's competitiveness in the next section. We employed the same design as Dohmen et al. (2010) to measure the mothers' risk preferences. ${ }^{5}$

At the daycare centers, we conducted experiments with the children to obtain behavioral measures of their willingness to compete and, as a control variable, their risk attitudes. Instead of

\footnotetext{
${ }^{5}$ Subjects made 20 choices between a lottery that paid out either 300 Euros or nothing with equal probability, and a fixed payment that increased from 0 to 180 Euros in increments of 10. Subjects were informed that one of their 20 choices would be randomly selected for potential payout, and that another random device decides with probability $1 / 9$ whether the earnings from the experiment would actually be paid out. To minimize the interviewer's influence, the laptop computer was turned towards the subject during the experiment so that the interviewer could not see the mothers' choices. The earnings from the experiment were paid out with a check that was sent by mail.
} 
using a computer and money, the children's experiments were embedded in a playful environment where they received plastic chips as payments that could be exchanged for different gifts at the end of the experiments. The children were informed that more attractive gifts could be obtained with more chips. In order to avoid confounding taste differences, we took great care in preventing the children from seeing the selection of toys while they actively participated in the experiment. ${ }^{6}$ Moreover, after a child completed all experiments and exchanged his or her chips for a gift, the chosen gift was placed in an opaque bag labeled with the child's name. The daycare center teacher then kept the bag until the end of the day to prevent the children from observing and being directly influenced by the gifts, as the experiments took place one after another.

Our experimental measure for competitiveness was elicited as follows. Children had to selfselect into either a piece rate or a tournament compensation scheme for a "real effort task." Children had to flip toy frogs into a toy pond that was placed at some distance so that scoring a hit required some skill. We conducted five non-incentivized trial rounds so that the children could become familiar with the task. We then asked each child which of two possible game alternatives he or she would like to play. In both games children received ten toy frogs, i.e., ten trials, and they were told to try to hit the pond as many times as possible. In the first game alternative, they would receive one chip for each frog that hit the pond (piece rate). In the second game alternative, they would receive 20 chips if they scored higher than another, randomly chosen child of same age and sex. However, if they scored less hits they would not receive any chips at all (tournament scheme). The rules of the two game alternatives were shown on a poster board and comprehension questions were asked to ensure their understanding. ${ }^{7}$ After a child made his or her decision but before the chosen game alternative was played, we also asked: "What do you

\footnotetext{
${ }^{6}$ However, there were a number of different gifts to ensure that each child could find a toy that attracts her or him.

${ }^{7}$ If a child could not answer the questions correctly, the procedure was explained again. If a child could not answer the question after three rounds of explanations, he or she would have been excluded from the study. However, all children were able to answer the comprehension questions correctly.
} 
think: will other children score rather higher or lower than you?" We use the answer to this question as a confidence measure in our regression analyses in the next section.

The children's risk preferences were elicited as follows (the design corresponds to the Gambling game in Hoffrage et al., 2003). A child was presented with 10 indistinguishable small boxes. They were told that 9 of the 10 boxes contained a chip, but that the figure of a robber was in one of the boxes. Children could open as many boxes as they wanted. They could keep all chips that were in the opened boxes but if they opened the box with the robber they lost all chips. The average number of unopened boxes serves as a measure of risk aversion. The fewer boxes a child opens, the more risk-averse is he or she. After the interviewer explained the rules of the game, a practice round was conducted to familiarize the children with the task and comprehension questions were asked to ensure the understanding of the rules. ${ }^{8}$ Finally, children had to choose how many boxes to open; they only received feedback on the content of the single boxes after having decided how many boxes to open. ${ }^{9}$

\section{Experimental Results}

To what extent are health conditions associated with a measure of non-cognitive skills in children? And how does the parents' socio-economic status affect the association between health conditions and non-cognitive skills? We address these questions in this section using our experimental measure of non-cognitive skills, i.e., whether a child self-selects into a competitive environment, and the information on the children's health condition taken from the household questionnaires their mothers completed. In particular, we have information whether a child had a medical condition forcing her or him to see a medical practitioner at least once in the last three months before the experiments took place. However, we do not know the type of medical

\footnotetext{
${ }^{8}$ The procedure was as in the competitiveness experiments (see footnote 7); all children understood the game.

${ }^{9}$ This strategy method of eliciting risk aversion makes sure that the obtained data on children's risk aversion do not suffer from a censoring problem.
} 
condition that initiated the child's visit of the medical practitioner nor do we know the number of visits. $^{10}$

We use linear probability models with robust standard errors and regress the choice for competition on the dummy Medical condition that indicates whether the child had to see a medical practitioner at least once in the last three month, controlling simultaneously for a number of other factors that potentially influence self-selection into competition. ${ }^{11}$ Descriptive statistics of all variables included in this study are shown in Table 1.

\section{[Include Table 1 about here]}

We find a large and statistically significant relationship between the propensity to select into competition and our measure of health condition (see column 1 of Table 2). Ceteris paribus, a child is about 11 percentage points less likely to self-select into competition if he or she had a medical condition at least once in the last three months.

We consider additional health measures as explanatory variables. The dummy Low birth weight takes on value one if a child's birth weight was below 2500 grams. This definition follows the International Statistical Classification of Diseases and Related Health Problems (World Health Organization 2007). Low birth weight is negatively but insignificantly associated with competitiveness. The dummy variable Low BMI has the value one if the child's body mass index is below the 10 percentile of the BMI distribution, and the variable High BMI indicates whether

\footnotetext{
${ }^{10}$ The question reads as follows: "Did you have to visit or call a doctor in the last three months because of medical conditions of your child?" The original formulation in German is: "Mussten Sie in den letzten drei Monaten wegen gesundheitlicher Probleme Ihres Kindes einen Arzt aufsuchen oder rufen?" While this measure clearly is an imperfect proxy for health status, it has the advantage that it does not require detailed pre-knowledge on the part of the mother answering the questionnaire.

${ }^{11}$ All findings from this paper also hold if we use probit or logit models instead of linear probability models. See also Table 2 for further information.
} 
the child's body mass index is above the 90 percentile of the BMI distribution. ${ }^{12}$ As a measure for Mental health we also include the SDQ Total Difficulties Score. ${ }^{13}$ While the variable High BMI is strongly negatively associated with competitiveness, none of the estimated coefficients is significant.

As additional control variables, the regression further includes Ability, which stands for the performance in the practice rounds and the dummy Confidence, which indicates whether a child expects to score rather more hits than the other children (see Section 2). We find that Confidence has a positive and significant effect, i.e., self-confident children are significantly more likely to self-select into the competitive environment. We also control for Risk aversion (measured in our risk experiment as the number of unopened boxes) because the tournament involves more risk than the piece rate. We find a negative association with the decision to enter competition, as expected, but the coefficient is very small and insignificant. We also include Age, a gender dummy Boy, Number of siblings, and Birth order. Birth order has a negative and significantly estimated coefficient, suggesting that earlier born children are more likely to be competitive. Number of siblings is positive and significant, suggesting that children with more siblings are more likely to be competitive. Age and gender are, however, not significant.

Cognitive skills are related to behavior in various economic experiments (e.g., Benjamin et al. 2006, Dohmen et al. 2010; Frederick 2005). We thus also control for $I Q$ but find no significant association with children's competitiveness. ${ }^{14}$ Finally, we control for the mother's risk preferences (measured in our household risk experiment, see footnote 5) because more risk-

\footnotetext{
${ }^{12}$ The respective percentiles cutoff-values that we use are gender and age specific and have been calculated based on values of a German calibration study (Kromeyer-Hauschild et al., 2001).

${ }^{13}$ The Strengths and Difficulties Questionnaire (SDQ) is a standardized questionnaire, first developed in England and specifically designed for children from age four to eleven (Goodman 2001). It has been officially translated into over 40 languages, and the German version has been systematically evaluated (Woerner et al. 2004). The SDQ asks for about 20 attributes, and parents rate each of the 20 items as being true, somewhat true, or certainly true. Our variable Mental health represents the Total Difficulties Score which is computed as the sum of all 20 items.

${ }^{14}$ We used a revised and shortened version of the Peabody Picture Vocabulary Test Revised (PPVT-R), which is an untimed individual intelligence test, taken from Tietze et al. (2005).
} 
averse mothers might be more cautious, thus more inclined to send their children to a medical practitioner. However, we do not find a significant association.

We summarize our observation on the association between child health and non-cognitive skills in the following:

Result 1: If a child had a medical condition at least once in the last three months, he or she selfselects less often into the competitive environment.

Recent studies have shown that child health can be an important explanation of disparities in children's cognitive development among different socio-economic groups (see, e.g., Case et al., 2005; Currie, 2009; Salm and Schunk, 2011). In the following we therefore analyze how the association of our measure of child health with competitiveness depends on the socio-economic status of the children's families.

To address this question we conducted a median split depending on the level of net household income and ran the same regression as specified above for the below-median and the above-median sample separately; see columns 2 and 3 of Table 2, respectively. We did this median split separately for the Munich and the Berlin sample, because - in line with official socio-demographic statistics - the two samples differ substantially with regard to their net household income. Mean net household income in the Munich sample is $4095 €$ per month (std. dev. $2471 €$ ), while mean net household income in the Berlin sample is $3024 €$ per month (std. dev. $1606 €)$.

In the sub-sample with low socio-economic background, a child is about 15 percentage points less likely to self-select into competition if he or she had a medical condition. However, we fail to find any association of our measure of health condition with competitiveness in the 
sub-sample with high socio-economic background. We summarize this observation in the following:

Result 2: The negative relation between health and competitiveness depends on the children's socio-economic status and is only significant in our sub-sample with low socio-economic status.

Our second result complements studies showing that the association between child health and cognitive skills differs by socio-economic background. Note that our result is about the differential association between child health and competitiveness and not about the level of competitiveness in the two sub-samples. Interestingly, as can be read from Table 1, the level of competitiveness is higher in the sub-sample with lower socio-economic background.

\section{[Include Table 2 about here]}

One explanation for our second finding could be that households with a higher socioeconomic background have more means to compensate for health deficits than households with a lower socio-economic background. ${ }^{15}$ Another interpretation could be that mothers with a higher socio-economic background are more cautious than mothers with a lower socio-economic background and are therefore more inclined to send their children to see a medical practitioner for minor reasons. In this case, the observation that a child had to see a medical practitioner would, on average, indicate less severe illnesses in the sub-sample with high socio-economic

\footnotetext{
${ }^{15}$ Similar to the association between medical condition and children's competitiveness, Table 2 shows a negative association between low birth weight and competitiveness in the sub-sample with lower socio-economic background, also suggesting that parents with lower socio-economic background might be less able to compensate for the corresponding health deficits. To our surprise, there is even a marginally significant positive association between low birth weight and competitiveness in the sub-sample with higher socio-economic background (this could indicate overcompensating care about low birth weight children in this sub-sample). Table 2 further shows a differential association for the birth order variable. Being of higher birth order is significantly negatively associated with competitiveness for children of lower socio-economic background but not for children of higher socio-economic background - a finding that could again be explained by more means of compensating for possible disadvantages in early childhood in the sub-sample with higher socio-economic background. While there are, to the best of our knowledge, no established findings on a direct causal effect of birth order on childhood health, it is, e.g., well known that birth order has a large negative effect on children's education (see, e.g., Black et al., 2005).
} 
background. However, we included our measure for a mother's risk aversion to control for her caution. Also, we find that the fraction of children who had to see a medical practitioner is very similar in the two sub-samples. In the sub-sample with income below median, 36.7 percent of the answers to this question were affirmative (std. dev. 0.48). In the sub-sample with income above median, 32.1 percent of the answers were affirmative (std. dev. 0.47). This difference between the sub-samples is not significant in a t-test $(\mathrm{p}=0.38)$.

\section{Conclusion}

In this paper, we asked two questions. First, to what extent are health conditions associated with non-cognitive skills in children? And second, is the parents' socio-economic status related to the association between health conditions and non-cognitive skills? The answers to these questions are of relevance, because a society's welfare and economic success depends crucially on the successful formation of human capital. The existing literature shows that child health can be an important explanation of disparities in children's cognitive development among different socioeconomic groups. This paper aims to be a first step to complement this literature by analyzing non-cognitive skills.

Specifically, we analyze data from economic experiments implemented in a household survey study with preschoolers and their mothers. We use the children's choices between a tournament and piece rate payment scheme, i.e., their competitiveness, as a measure of noncognitive skills. Our measure for health condition is based on the information whether a child had to see a medical practitioner due to a medical condition at least once during the last three months before the experiments took place. We find that our health measure is negatively and significantly associated with children's self-selection into the competitive environment. Moreover, we find that the association between health and competitiveness differs by socio-economic background: it 
is strong and significant in our sub-sample with low socio-economic background and virtually absent in families in our sub-sample with high socio-economic status.

Our results suggest, first, that health might be a pathway for the formation of human capital not only for cognitive but also for non-cognitive skills. Second, it suggests that favorable family conditions might be able to overcome the negative effects of health problems on noncognitive skill development. The second result is especially surprising, given that the health care system in Germany, where the study was conducted, is characterized by almost universal health insurance coverage and a focus on child health and prevention programs: 99.8 percent of the German population are enrolled in mandatory health insurance, and those who are not enrolled are mostly the very rich (German Federal Statistical Office 2004). The almost universal health care coverage thus shows that differential access to the health care system does not drive our results. Rather, disadvantages in the development of human capital seem to arise in family environments that cannot compensate for the adverse consequences of health problems.

These interpretations of our empirical results should be taken with a grain of salt, however, first because they are based on only one particular and contemporaneous measure of child health and on one particular and contemporaneous measure of non-cognitive skills. Second, unobserved third factors, such as differences in parenting style might underlie the findings. We are thus not able to precisely pin down the mechanisms behind our results. Further progress on the questions raised in this paper would ideally require, among others, sibling data to control for family unobserved factors, panel data about childhood skill and health development with more information on the severity of health conditions, as well as detailed time use data to measure parental inputs. 


\section{References}

Aughinbaugh, A. and M. Gittleman (2003), "Does Money Matter? A Comparison of the Effect of Income on Child Development in the United States and Great Britain," The Journal of Human Resources, 38(2), 416-40.

Behrman, J. and M. Rosenzweig (2004), "Returns to Birthweight," Review of Economics and Statistics, 86, $586-601$.

Benjamin, D. J., S. A. Brown, and J. M. Shapiro (2007), "Who is 'Behavioral'? Cognitive Ability and Anomalous Preferences," SSRN-Working Paper No. 675264.

Bettinger, E., and R. Slonim (2007), "Patience among children," Journal of Public Economics, $91,343-363$.

Black, S.E., Devereux, P. J. and K. G. Salvanes (2005), “The More the Merrier? The Effect of Family Size and Birth Order on Children's Education." Quarterly Journal of Economics, 120(2), 669-700.

Blau, D. (1999), “The effect of income on child development," Review of Economics and Statistics, 81, 261-76.

Case, A., D. Lubotsky, and C. Paxson (2002), "Economic Status and Health in Childhood: The Origins of the Gradient," American Economic Review, 92, 1308-34.

Case, A., A. Fertig, and C. Paxson (2005), “The Lasting Impact of Childhood Health and Circumstance," Journal of Health Economics, 24, 365-89.

Cunha, F. and J. Heckman (2007), "The Technology of Skill Formation,” American Economic Review, 97(2), 31-47.

Cunha, F. and J. Heckman (2009), "The Economics and Psychology of Inequality and Human Development," Journal of the European Economic Association, 7(2-3), 320-364.

Currie, J. (2009), "Healthy, Wealthy and Wise: Socio-economic Status, Poor Health in Childhood, and Human Capital Development," Journal of Economic Literature, 47(1), 87122.

Currie, A., M. Shields, and S. Price (2007), "Is the child health / family income gradient universal? Evidence from England," Journal of Health Economics, 26, 212-32.

Currie, J. and M. Stabile (2003), "Socio-economic status and child health: Why is the relationship stronger for older children?" American Economic Review, 93, 1813-23. 
Currie, J., Stabile, M., Manivong, P., and L. Roos (2010), “Child Health and Young Adult Outcomes," Journal of Human Resources, 45(3), 517-548..

Dohmen, T., A. Falk, D. Huffman, and U. Sunde (2009), "Homo reciprocans: Survey evidence on behavioral outcomes," Economic Journal, 119, 592-612.

Dohmen, T., A. Falk, D. Huffman, and U. Sunde (2010), “Are Risk Aversion and Impatience related to Cognitive Ability?" American Economic Review, 100(3), 1238-1260..

Dustmann, C. Rajah, N. and van Soest, A. (2003), "Class size, education and wages," Economic Journal, 113, 99-120.

Frederick, S. (2005), “Cognitive Reflection and Decision Making,” Journal of Economic Perspectives, 19(4), 24-42.

German Federal Statistical Office (2004), "Krankenversicherung in Deutschland. Sonderauswertung des Mikrozensus 2003," Wiesbaden.

Goodman, R. (2001), „Psychometric Properties of the Strengths and Difficulties Questionnaire (SDQ)," Journal of the American Academy of Child \& Adolescent Psychiatry, 40, 1337-45.

Heckman, J. J. (2007), “The economics, technology, and neuroscience of human capability formation," Proceedings of the National Academy of Sciences, 104, 13250-55.

Heckman, J., J. Stixrud and S. Urzua (2006), “The Effects of Cognitive and Non-cognitive Abilities on Labor Market Outcomes and Social Behavior," Journal of Labor Economics, 24(3), 411-82.

Hoffrage, U., Weber, A., Hertwig, R., and Chase, V. M. (2003), "How to keep children safe in traffic: Find the daredevils early," Journal of Experimental Psychology: Applied, 9, 249-60.

Knight, Jonathan (2002), “Sexual Stereotypes," Nature, 415, 254-56.

Knudsen, Eric I., James J. Heckman, Judy L. Cameron, and Jack P. Shonkoff (2006), “Economic, neurobiological, and behavioral perspectives on building America's future workforce," Proceedings of the National Academy of Science, 103(27), 10155-62.

Kromeyer-Hauschild, K., M. Wabitsch, D. Kunze, F. Geller, H. C. Geiß, V. Hesse, A. von Hippel, U. Jaeger, D. Johnsen, W. Korte, K. Menner, G. Müller, J. M. Müller, A. NiemannPilatus, T. Remer, F. Schaefer, H.-U. Wittchen, S. Zabransky, K. Zellner, A. Ziegler and J. Hebebrand (2001), "Perzentile für den Body-Mass-Index für das Kindes- und Jugendalter unter Heranziehung verschiedener deutscher Stichproben," Monatsschrift Kinderheilkunde, 149(8), 807-18. 
Little, R.J.A. and D.B. Rubin (2002), “Statistical Analysis with Missing Data,” Wiley, New York.

Niederle, M., and L. Vesterlund (2007), "Do Women Shy Away from Competition? Do Men Compete to Much?" Quarterly Journal of Economics, 122(3), 1067-1101.

Shonkoff, J. and D. Phillips (2000), "From Neurons to Neighbourhoods: The Science of Early Childhood Development," National Academic Press, Washington, DC.

Paxson, C. and N. Schady (2007), "Cognitive development among young children in Ecuador," Journal of Human Resources, 42, 49-84.

Salm, M. and D. Schunk (2011), “The relationship between child health, developmental gaps, and parental education: Evidence from administrative data," Journal of the European Economic Association, forthcoming.

Sutter, M. and D. Rützler (2010), “Gender differences in competition emerge early in life,” IZA Discussion Paper 5015. IZA, Bonn, Germany.

Taylor, B. A., E. Dearing, and K. McCartney (2004), "Incomes and Outcomes in Early Childhood," Journal of Human Resources, 39(4), 980-1007.

Tietze, W., Rossbach, H.-G., and Grenner, K. (2005), “Kinder von 4 bis 8 Jahren. Zur Qualität der Erziehung und Bildung in Kindergarten, Grundschule und Familie,” Beltz, Weinheim and Basel.

Woerner, W., A. Becker and A. Rothenberger (2004), "Normative data and scale properties of the German parent SDQ," European Child \& Adolescent Psychiatry, 13, 3-10.

World Health Organization (2007), "International Statistical Classification of Diseases (ICD)," http://www.who.int/classifications/apps/icd/icd10online/?gp05.htm+p05, accessed February 1, 2010. 
TABLE 1: Descriptive Statistics

\begin{tabular}{|c|c|c|c|c|c|c|c|c|c|}
\hline \multirow[b]{2}{*}{ Variable } & \multicolumn{5}{|c|}{ Full sample } & \multicolumn{2}{|c|}{$\begin{array}{l}\text { Parents' income } \\
\text { below median }\end{array}$} & \multicolumn{2}{|c|}{$\begin{array}{l}\text { Parents' income } \\
\text { above median }\end{array}$} \\
\hline & Min & Max & Mean & Median & Std. Dev. & Mean & Std. Dev. & Mean & Std. Dev. \\
\hline Competition & 0 & 1 & 0.341 & 0 & 0.47 & 0.392 & 0.49 & 0.290 & 0.46 \\
\hline Medical condition & 0 & 1 & 0.345 & 0 & 0.48 & 0.367 & 0.48 & 0.321 & 0.47 \\
\hline Low birth weight & 0 & 1 & 0.067 & 0 & 0.25 & 0.096 & 0.30 & 0.037 & 0.19 \\
\hline Low BMI & 0 & 1 & 0.180 & 0 & 0.38 & 0.163 & 0.37 & 0.198 & 0.40 \\
\hline High BMI & 0 & 1 & 0.064 & 0 & 0.25 & 0.072 & 0.26 & 0.056 & 0.23 \\
\hline Mental Health & 0 & 25 & 4.595 & 4 & 3.37 & 5.199 & 3.65 & 3.975 & 2.94 \\
\hline Ability & 0 & 7 & 1.716 & 2 & 1.27 & 1.699 & 1.23 & 1.735 & 1.31 \\
\hline Confident & 0 & 1 & 0.552 & 1 & 0.50 & 0.554 & 0.50 & 0.549 & 0.50 \\
\hline Risk aversion & 1 & 9 & 4.780 & 5 & 2.13 & 4.596 & 2.02 & 4.970 & 2.23 \\
\hline Age (in years) & 4 & 7 & 5.384 & 5 & 0.54 & 5.361 & 0.56 & 5.407 & 0.52 \\
\hline Boy & 0 & 1 & 0.506 & 1 & 0.50 & 0.494 & 0.50 & 0.519 & 0.50 \\
\hline Number of siblings & 0 & 11 & 1.073 & 1 & 1.02 & 1.048 & 1.17 & 1.099 & 1.10 \\
\hline Birth order & 1 & 10 & 1.561 & 1 & 0.86 & 1.560 & 0.94 & 1.562 & 0.78 \\
\hline$I Q$ & 23 & 60 & 44.957 & 46 & 6.27 & 44.783 & 6.19 & 45.136 & 6.36 \\
\hline Risk aversion mother & 1 & 21 & 9.970 & 10 & 5.55 & 9.801 & 5.73 & 10.142 & 5.36 \\
\hline Net household income & 400 & 20,000 & 3,406 & 3,000 & 2,022 & 2,122 & 685 & 4,721 & 2,092 \\
\hline
\end{tabular}

Notes: Competition takes on value 1 if the child self-selected into the competitive scheme. Medical condition takes on value 1 if the child had a medical condition at least once in the three months before the experiments took place. Low birth takes on value 1 if a child's birth weight was below 2500 grams. Low BMI has value 1 if the child's body mass index (BMI) is below the 10 percentile and High BMI has value 1 if the child's BMI is above the 90 percentile of the BMI distribution. Mental health shows the SDQ Total Difficulties Score. Ability is the performance in the practice rounds of the real effort task. Confidence takes on value 1 if a child expects to score more hits than the other children. Risk aversion is the number of unopened boxes in our risk elicitation game. IQ shows the child's score in a Peabody Picture Vocabulary Test. Risk aversion mother is the switching point in the risk elicitation price list. Net household income is in €/month. Note that our analyses are based on 328 observations. From the original sample of 332 observations, 4 could not be used: In one observation no information on the mother's risk aversion was obtained (variable Risk aversion mother), in another observation the mother did not answer the SDQ-questionnaire (variable Mental health). For two children, information on the variable Ability is missing. Of the remaining sample of 328 children, there was no information on net household income for 5.8\% of the sample $(\mathrm{n}=19)$. This information was imputed using regression-based imputation (see, e.g., Little and Rubin, 2002) in which we condition on mothers' and fathers' education, homeownership, the number of books per household, and marital status. 
TABLE 2: Regression Models

(1)

\begin{tabular}{|c|c|c|c|}
\hline & Full sample & $\begin{array}{l}\text { Parents' income } \\
\text { below median }\end{array}$ & $\begin{array}{l}\text { Parents' income } \\
\text { above median }\end{array}$ \\
\hline Medical condition & $\begin{array}{c}-0.105 * * \\
(0.053)\end{array}$ & $\begin{array}{c}-0.153 * * \\
(0.075)\end{array}$ & $\begin{array}{c}0.013 \\
(0.079)\end{array}$ \\
\hline Low birth weight & $\begin{array}{l}-0.027 \\
(0.122)\end{array}$ & $\begin{array}{c}-0.320 * * \\
(0.129)\end{array}$ & $\begin{array}{l}0.366^{*} \\
(0.218)\end{array}$ \\
\hline Low BMI & $\begin{array}{c}0.002 \\
(0.070)\end{array}$ & $\begin{array}{l}-0.054 \\
(0.106)\end{array}$ & $\begin{array}{c}0.027 \\
(0.086)\end{array}$ \\
\hline High BMI & $\begin{array}{l}-0.135 \\
(0.095)\end{array}$ & $\begin{array}{l}-0.161 \\
(0.137)\end{array}$ & $\begin{array}{l}-0.139 \\
(0.159)\end{array}$ \\
\hline Mental Health & $\begin{array}{c}0.008 \\
(0.008)\end{array}$ & $\begin{array}{l}-0.002 \\
(0.011)\end{array}$ & $\begin{array}{c}0.005 \\
(0.011)\end{array}$ \\
\hline Ability & $\begin{array}{c}0.018 \\
(0.020)\end{array}$ & $\begin{array}{l}0.052^{*} \\
(0.031)\end{array}$ & $\begin{array}{l}-0.013 \\
(0.028)\end{array}$ \\
\hline Confident & $\begin{array}{c}0.176^{* * * *} \\
(0.052)\end{array}$ & $\begin{array}{c}0.220 * * * \\
(0.077)\end{array}$ & $\begin{array}{c}0.178 * * \\
(0.072)\end{array}$ \\
\hline Risk aversion & $\begin{array}{l}-0.005 \\
(0.012)\end{array}$ & $\begin{array}{c}0.006 \\
(0.018)\end{array}$ & $\begin{array}{l}-0.019 \\
(0.015)\end{array}$ \\
\hline Age & $\begin{array}{c}0.077 \\
(0.053)\end{array}$ & $\begin{array}{c}0.048 \\
(0.071)\end{array}$ & $\begin{array}{c}0.110 \\
(0.074)\end{array}$ \\
\hline Boy & $\begin{array}{l}-0.038 \\
(0.052)\end{array}$ & $\begin{array}{c}0.030 \\
(0.077)\end{array}$ & $\begin{array}{l}-0.094 \\
(0.076)\end{array}$ \\
\hline Number of siblings & $\begin{array}{l}0.074^{*} \\
(0.040)\end{array}$ & $\begin{array}{c}0.148 * * * \\
(0.048)\end{array}$ & $\begin{array}{c}0.010 \\
(0.059)\end{array}$ \\
\hline Birth order & $\begin{array}{c}-0.106^{* *} \\
(0.048)\end{array}$ & $\begin{array}{c}-0.202 * * * \\
(0.062)\end{array}$ & $\begin{array}{l}-0.014 \\
(0.067)\end{array}$ \\
\hline$I Q$ & $\begin{array}{c}0.004 \\
(0.005)\end{array}$ & $\begin{array}{l}0.013 * \\
(0.007)\end{array}$ & $\begin{array}{l}-0.002 \\
(0.007)\end{array}$ \\
\hline Risk aversion mother & $\begin{array}{l}-0.004 \\
(0.005)\end{array}$ & $\begin{array}{c}0.003 \\
(0.007)\end{array}$ & $\begin{array}{c}-0.014 * * \\
(0.006)\end{array}$ \\
\hline Constant & $\begin{array}{l}-0.138 \\
(0.317)\end{array}$ & $\begin{array}{l}-0.255 \\
(0.440)\end{array}$ & $\begin{array}{c}0.032 \\
(0.446)\end{array}$ \\
\hline $\begin{array}{l}\text { Observations } \\
R^{2}\end{array}$ & $\begin{array}{l}328 \\
0.10 \\
\end{array}$ & $\begin{array}{l}166 \\
0.20\end{array}$ & $\begin{array}{l}162 \\
0.13 \\
\end{array}$ \\
\hline
\end{tabular}

Notes: The table reports the estimation results of a linear probability model (robust standard errors in parentheses). The dependent variable is a dummy variable indicating whether the child has chosen to compete. Parents' educational status and log household income are included as additional controls, all being insignificant. Significance levels are denoted as follows: $* \mathrm{p}<0.1,{ }^{* *}$ $\mathrm{p}<0.05, * * * \mathrm{p}<0.01$. The findings reported above are robust to using probit or logit models. For a logit model, the marginal effect of the variable Medical condition, evaluated at the median of the covariates, is $-0.122 * *(0.064)$ for the full sample, $-0.180^{* *}(0.089)$ for the sample with parent's income below median, and $0.022(0.074)$ for the sample with parent's income above median. The values for a probit model are $-0.120 * *(0.061)$ for the full sample, $-0.173 * *(0.087)$ for the below median sample, and $0.032(0.074)$ for the above median sample. 